\title{
Taller de Derecho
}

\section{PRESENTACIÓN}

El Taller de Derecho es una asociación de estudiantes de la Facultad de Derecho de la Pontificia Universidad Católica del Perú. Fue fundada en 1977 y tiene como finalidades la investigación jurídica y la difusión del Derecho con miras a brindar una formación integral a los estudiantes de nuestra casa de estudios. Con el fin de abarcar las principales disciplinas jurídicas, el Taller de Derecho se compone de equipos de estudio, entre ellos, el equipo de Derecho internacional y derechos humanos, el de Derecho mercantil, el de Derecho ambiental, el de Derecho constitucional, el de Derecho tributario, el de Derecho penal y el de Derecho laboral y de la seguridad social (este último hizo su ingreso oficialmente el sábado 6 de febrero de 2010).

\section{OBJETIVOS}

El Taller de Derecho tiene como principal objetivo fomentar un espacio de investigación jurídica para todos sus miembros. Busca profundizar los conocimientos de estos, al debatir sobre las materias analizadas y con la finalidad última de presentarlas hacia la comunidad universitaria de la Universidad Católica y la comunidad en general.

De esta forma, el Taller de Derecho constituye en principal círculo estudiantil institucionalizado de la Pontificia Universidad Católica del Perú que se dedica a la labor de investigación de los distintos temas de Derecho. A partir de ello, brinda a los estudiantes de Derecho la oportunidad de desarrollar y de reforzar sus conocimientos sobre distintas áreas de la materia, así como también de colaborar con su difusión mediante la organización de eventos como ferias académicas, seminarios y conversatorios, entre otros.

\section{III.VISIÓN DEL TALLER DE DERECHO SOBRE RESPONSABILIDAD SOCIAL}

En la actualidad, la responsabilidad social juega un papel importante en las actividades del abogado: ya no se trata solo de defender a los clientes o de ofrecer una buena asesoría, sino que también es oportuno saber qué consecuencias produce esa actividad en nuestro alrededor. El éxito del abogado también involucra el desarrollo del mundo que lo rodea: clientes, socios, empleados y comunidad en general. En este caso, el Taller de Derecho no solo funciona como un círculo de estudios que busca 
el beneficio de sus miembros; nuestro actuar como asociación también debe tener en cuenta la participación de los alumnos de la Facultad y de la comunidad en general.

La responsabilidad social del Taller de Derecho también se centra en la formación de nuestros miembros a través del debate de temas de actualidad jurídica y de hechos públicos que tienen incidencia jurídica, los cuales son importantes para la comunidad en general por las consecuencias que ocasionaría tomar una decisión al respecto.

El Taller de Derecho está comprometido con las demandas sociales de personas y grupos que sufren la vulneración de sus derechos. Dichas demandas son presentadas a los alumnos de la Facultad para informar sobre la implicancia social y jurídica que existe. De esta forma, se hace participar al alumno en hechos externos y se crea en él conciencia social y jurídica.

\section{ACTIVIDADES DEL TALLER DE DERECHO}

La visión de responsabilidad social se centra en el objetivo de difundir el Derecho dentro y fuera de nuestra casa de estudios. Dentro de ella, las actividades de responsabilidad social del Taller de Derecho guardan una línea académica. Se preocupa por que el alumno de nuestra Facultad pueda acceder de manera gratuita a información jurídica actual, presente a través de publicaciones semestrales que los equipos distribuyen en formato físico o electrónico. Entre las publicaciones, podemos mencionar los boletines del equipo de Derecho mercantil y del de Derecho constitucional. Estos se entregan a autoridades, profesores y alumnos de la Facultad, e incluyen artículos de sus miembros y de abogados especialistas en los temas tratados. En el mismo sentido, es importante mencionar que el equipo de Derecho laboral y seguridad social publicará un boletín en el presente semestre 2010-1.

Otra manifestación importante de responsabilidad social dentro de la Facultad es la organización de eventos académicos que, en su gran mayoría, son gratuitos. Durante ellos, se exponen temas actuales de debate jurídico en la sociedad. Los eventos académicos se caracterizan por presentar ponentes que poseen distintos puntos de vista del tema tratado. De esta forma, se persigue el debate jurídico y no caer en una simple exposición de los hechos. El equipo de Derecho ambiental supone una clara manifestación de esta dinámica de trabajo, pues presenta temas jurídicos actuales en materia ambiental y tiene como ponentes a personas de diversas disciplinas, lo que hace del evento un espacio de debate intenso.

Las actividades de responsabilidad social del Taller de Derecho fuera de nuestra casa de estudios se hacen presentes a través de los pronunciamientos que se emiten en favor de personas o de grupos cuyos derechos 
son vulnerados. Los pronunciamientos se caracterizan por tener solo un análisis jurídico del hecho tratado. Entres los pronunciamientos que realizó el Taller de Derecho, se encuentra el caso (14 de septiembre de 2009) de discriminación al doctor Edwin Béjar Rojas, abogado cusqueño egresado de la Universidad San Antonio Abad del Cusco, que fue excluido del proceso de selección, sin motivo razonable, para una plaza de fiscal adjunto provincial en la ciudad del Cusco.

De la misma forma, podemos mencionar el pronunciamiento que emitió el equipo de Derecho ambiental, el 28 de septiembre de 2009, sobre el programa de ampliación y manejo ambiental (PAMA) de Doe Run Perú. Se expresó que en el país la protección ambiental aún se encuentra en un segundo plano, y se rescató su importancia social y necesidad publica, vulnerada a través de hechos como la contaminación del medio ambiente en la ciudad de La Oroya.

Actualmente, el Taller de Derecho es un espacio académico donde sus miembros tienen la tarea de contribuir, a través de sus investigaciones, al desarrollo social de la comunidad en general. 